Article

\title{
Thermal Healing, Reshaping and Ecofriendly Recycling of Epoxy Resin Crosslinked with Schiff Base of Vanillin and Hexane-1,6-Diamine
}

\author{
Van-Dung Mai ${ }^{1,+} \mathbb{C}$, Se-Ra Shin ${ }^{1,+} \mathbb{D}$, Dai-Soo Lee ${ }^{1, * \mathbb{C}}$ and Ilho Kang ${ }^{2, *}$ \\ 1 Division of Semiconductor and Chemical Engineering, Chonbuk National University, Baekjedaero 567, \\ Deokjin-gu, Jeonju, Chonbuk 54896, Korea; dungmv1983@gmail.com (V.-D.M.); \\ srshin89@jbnu.ac.kr (S.-R.S.) \\ 2 Research Center, NEPES AMC, 99 Seokam-ro, Iksan, Chonbuk 54587, Korea \\ * Correspondence: daisoolee@jbnu.ac.kr (D.-S.L.); kangilho@nepesamc.co.kr (I.K.); \\ Tel.: +82-63-270-2310 (D.-S.L.); +82-63-833-2020 (I.K.) \\ + These authors contributed equally to this work.
}

Received: 1 February 2019; Accepted: 8 February 2019; Published: 10 February 2019

\begin{abstract}
A bio-derived dihydroxylimine hardener, Van2HMDA, for the curing of epoxy resin was prepared from vanillin (Van) and hexamethylene-1,6-diamine (HMDA) by Schiff base formation. The epoxy resin of diglycidyl ether of bisphenol A was cured with Van2HMDA in the presence of the catalyst, 2-ethyl-4-methylimidazole (EMI). The crosslinked epoxy resin showed thermal-healing properties at elevated temperatures. Moreover, the crosslinked epoxy resin can be reshaped by heating via imine metathesis of the hardener units. The imine metathesis of Van2HMDA was confirmed experimentally. Stress-relaxation properties of the epoxy resin crosslinked with Van2HMDA were investigated, and the activation energy obtained from Arrhenius plots of the relaxation times was $44 \mathrm{~kJ} / \mathrm{mol}$. The imine bonds in the epoxy polymer matrix did not undergo hydrolysis after immersing in water at room temperature for one week. However, in the presence of acid, the crosslinked polymer was easily decomposed due to the hydrolysis of imine bonds. The hydrolysis of imine bonds was used for the ecofriendly recycling of crosslinked polymer. It is inferred that thermal-healing, reshaping, and reprocessing properties can be implemented in the various crosslinked epoxy resins with the bio-derived dihydroxylimine hardener, albeit the recycled epoxy resin is of inevitably lower quality than the original material.
\end{abstract}

Keywords: crosslinked epoxy resin; thermal-healing; recycling; imine metathesis; bio-derived hardener

\section{Introduction}

Epoxy resin is a representative thermosetting polymer that has been widely used because of its excellent thermal and chemical stability and good mechanical properties. However, because, upon curing, epoxy resins form a highly crosslinked network structure, they cannot be reshaped or recycled at the end of their service life or after they have been damaged and may pose a risk to the environment and to human health. Therefore, extensive efforts have been devoted to designing thermosetting epoxy resins that can be reshaped or recycled and to extending the lifetimes of epoxy resins by introducing healing properties.

The first strategy to introduce healing properties into epoxy resins involves introducing containers or capsules that contain a healing agent [1-3]. In this method, when a crack is formed, the capsules are broken, thereby releasing the healing agent to heal the crack. This extrinsic healing strategy has limitations with respect to repeated healing capability, and the epoxy resin still cannot be reshaped or recycled after crosslinking. The second strategy for healing capability is the introduction of dynamic 
covalent bonds into the polymer matrix. This intrinsic healing can be classified into one of two types-dissociative or associative-based on the mechanism.

In the dissociative-type mechanism, chemical bonds are first broken upon stimulus and, then, formed again under a different stimulus. The typical dissociative-type mechanism is based on a Diels-Alder reaction [4-7]. Heating of products crosslinked by a Diels-Alder reaction induces a retro Diels-Alder reaction that accompanies the dissociation of the crosslinked structure and a decrease in viscosity that enables the damaged parts of the polymer to heal. However, upon cooling, the Diels-Alder reaction cannot proceed to completion and the polymer cannot be restored its original crosslinking density.

In the associative-type mechanism, dynamic covalent bonds are broken and are reformed at the same time. Because of the nature of the exchange reactions, the crosslink structures are maintained; however, the viscosity of the polymer can be controlled, enabling the epoxy thermoset to be processed like a thermoplastic [8-20] at elevated temperatures. The thermosetting epoxy resins containing such bonds have properties similar to those of a conventional thermoset at temperatures below a critical temperature (i.e., the vitrification temperature); however, at temperatures above this temperature, its behavior is similar to that of thermoplastics in general [8]. Examples of the exchange reactions include transesterification [8-11], metatheses of disulfides [12-16], olefins [17], boronic esters [18,19], and acylhydrazones [20]. Another type of linkage that can undergo exchange reactions is the $\mathrm{C}=\mathrm{N}$ bond of an imine or Schiff base. The imine compounds can be easily synthesized by a condensation reaction between a primary amine and an aldehyde or ketone [21]. The reversible reaction of $\mathrm{C}=\mathrm{N}$ includes hydrolysis (reaction with water), transamination (reaction with another primary amine), and imine metathesis (reaction with another imine bond). The mechanism of the imine exchange reaction in an organic solvent has been studied [22] which has revealed that imine metathesis proceeds faster under mild conditions in the presence of a small amount of primary amine as a catalyst. The imine bond has also been used to design polyimines with healing and recycling ability [23-25] and applied in self-assembly polymers [26-28]. The thermal-healing epoxy resin system based on imine metathesis has been reported [29]. However, this polymer shows low glass-transition temperature and low tensile strength in comparison with epoxy polymers composed of ester bonds [8] or disulfides bonds [12,13].

Concerning the environmental issue, petroleum-based materials should be replaced with bio-based materials from renewable resources. Among bio-based materials that can be incorporated into epoxy resin systems, vanillin (Van; 4-hydroxy-3-methoxybenzaldehyde) has been used to prepare epoxy resins [30-32]. Natural vanillin is one of the components extracted from vanilla orchid pods, which is widely used in food industry. However, the Van used in industries is not sourced natural vanillin to minimize the production cost as natural vanillin is expensive. Synthetic vanillin is industrially produced based on petroleum raw material and biomaterial such as wood. Among the biomaterials, lignin is a promising material [33] because this is a byproduct of the paper industry. In the present work, we present a simple route to prepare a bio-derived dynamic hardener (Scheme 1) for epoxy resin and study on its curing behavior as well as its thermal-healing, reshaping, and recycling abilities.

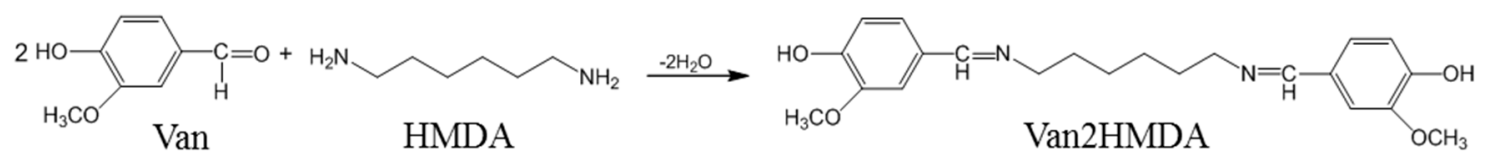

Scheme 1. Condensation reaction of Van with hexane-1,6-diamine (HMDA) to prepare the Schiff base, Van2HMDA. 


\section{Materials and Methods}

\subsection{Materials}

Hexane-1,6-diamine (HMDA), vanillin, 4-hydroxylbenzaldehyde (HBA), and 2-ethyl-4methylimidazole (EMI) as a catalyst were purchased from Sigma-Aldrich (Yong-In, Korea). A diglycidyl ether of bisphenol A (DGEBA)-based epoxy resin with an epoxy equivalent weight of $187 \mathrm{~g} / \mathrm{eq}$ (YD-128) was provided by Kukdo Chemical (Seoul, South Korea). Solvents used in this work include ethanol $(\mathrm{EtOH})$, methanol $(\mathrm{MeOH})$, toluene (Tol), dimethylformamide (DMF), and dimethylacetamide (DMAc), which were supplied by Samchun Pure Chemical (Pyeong-Taek, South Korea). All materials were used without further purification.

\subsection{Preparation of Dihydroxylimine Compound}

Van ( $30.43 \mathrm{~g}, 0.2 \mathrm{~mol})$ was dissolved in $200 \mathrm{ml}$ of EtOH followed by the addition of HMDA (11.62 g, $0.1 \mathrm{~mol}$ ). The mixture was heated and was magnetically stirred at $80^{\circ} \mathrm{C}$ for $12 \mathrm{~h}$. A yellow precipitate was observed after the HMDA was dissolved in the Van solution. The precipitate, a dihydroxylimine compound (Van2HMDA), was collected by filtration, washed with cold $\mathrm{EtOH}$ and, then, was dried under vacuum at $70{ }^{\circ} \mathrm{C}$ for $24 \mathrm{~h}$. The dried yellow powder $\left(35.28 \mathrm{~g}\right.$, yield: $\left.91.76 \%, \mathrm{mp}=129-130{ }^{\circ} \mathrm{C}\right)$. ${ }^{1} \mathrm{H}$ NMR (DMSO-d6, $\left.600 \mathrm{MHz}\right)$ chemical shift ( $\left.\delta, \mathrm{ppm}\right): 8.10(2 \mathrm{H},-\mathrm{CH}=\mathrm{N}-), 7.27(2 \mathrm{H}, \mathrm{Ar}-\mathrm{H}), 7.04$ $(2 \mathrm{H}, \mathrm{Ar}-\mathrm{H}), 6.77(2 \mathrm{H}, \mathrm{Ar}-\mathrm{H}), 3.75(6 \mathrm{H},-\mathrm{OCH} 3), 3.44(4 \mathrm{H},-\mathrm{CH} 2-$ in hexane methylene), $1.54(4 \mathrm{H}$, - $\mathrm{CH} 2-$ in hexane methylene), $1.30\left(4 \mathrm{H},-\mathrm{CH} 2-\right.$ in hexane methylene). ${ }^{13} \mathrm{C}$ NMR (DMSO-d6, $\left.600 \mathrm{MHz}\right)$ $\delta$ (ppm): $160.47(-\mathrm{CH}=\mathrm{N}-), 148.44,123.05,115.72,110.37$ (C of Ar), 60.81 (-OCH3), 55.96 (-CH2-), 31.13, $27.15(-\mathrm{CH} 2-)$.

The model compound based on HMDA and HBA, HBA2HMDA, was prepared via a similar process and was characterized by NMR analysis. ${ }^{1} \mathrm{H}$ NMR (DMSO-d6, $\left.600 \mathrm{MHz}\right) \delta(\mathrm{ppm}): 8.11(2 \mathrm{H}$, $-\mathrm{CH}=\mathrm{N}-), 7.48-7.50(4 \mathrm{H}, \mathrm{Ar}-\mathrm{H}), 6.74-6.76(4 \mathrm{H}, \mathrm{Ar}-\mathrm{H}), 3.41-3.43\left(4 \mathrm{H},-\mathrm{CH}_{2}-\right.$ in hexane methylene), 1.51-1.53 (4H, $-\mathrm{CH}_{2}-$ in hexane methylene), $1.27-1.29\left(4 \mathrm{H},-\mathrm{CH}_{2}-\right.$ in hexane methylene). ${ }^{13} \mathrm{C}$ NMR (DMSO-d6, $600 \mathrm{MHz}) \delta(\mathrm{ppm}): 160.26(-\mathrm{CH}=\mathrm{N}-), 130.00,128.04,115.92$, (C of Ar), $60.94\left(-\mathrm{CH}_{2}-\right), 31.18$, $27.16\left(-\mathrm{CH}_{2}-\right)$.

\subsection{Curing of Bisphenol A-Based Epoxy Resin by Van2HMDA}

A stoichiometric mixture of epoxy resin (YD-128, $10 \mathrm{~g}$ ) and Van2HMDA (10.28 g) was heated and was mechanically stirred at $140{ }^{\circ} \mathrm{C}$ in a $250 \mathrm{~mL}$ reactor until the resin mixture was homogeneous. The resin was cooled to $100^{\circ} \mathrm{C}$ followed by the addition of the EMI catalyst (1 wt \%) under stirring for an additional $1 \mathrm{~min}$. Then, the resin was cast and was cured at $120^{\circ} \mathrm{C}$ for $24 \mathrm{~h}$ and, subsequently, post-cured further at $150{ }^{\circ} \mathrm{C}$ for $2 \mathrm{~h}$ to obtain a 1-mm-thick film.

\subsection{Recycle of Crosslinked Epoxy Polymer Cured by Van2HMDA}

The crosslinked epoxy polymer was recycled through the following procedure. Typically, $8 \mathrm{~g}$ of cured epoxy resin was added to $200 \mathrm{~mL}$ of $0.1 \mathrm{~mol} / \mathrm{L} \mathrm{HCl}$ standard solution. After the solution was heated and stirred at $70^{\circ} \mathrm{C}$ for about $8 \mathrm{~h}$, all polymer was dissolved. The solvent was removed by rotary evaporator at $65^{\circ} \mathrm{C}$. The hydrolyzed polymer was dried at $80^{\circ} \mathrm{C}$ for $24 \mathrm{~h}$ and further $110{ }^{\circ} \mathrm{C}$ for $24 \mathrm{~h}$ to remove residue solvent and recover the polymer network by the condensation reaction.

\subsection{Methods}

The FT-IR spectra were recorded with a Jasco FT/IR 4100 (JASCO, Easton, MD, USA). The solid samples for FT-IR spectroscopy were mixed with $\mathrm{KBr}$ powder; then, they were ground, and pressed into thin tablets. The liquid samples were scanned after being coated directly onto $\mathrm{KBr}$ tablets. 
The ${ }^{1} \mathrm{H}$ NMR and ${ }^{13} \mathrm{C}$ NMR spectra were collected with a $600 \mathrm{MHz}$ FT-NMR spectrometer (JNM-ECA600, JEOL Ltd., Tokyo, Japan). The samples ( 30 mg) were dissolved in $0.75 \mathrm{~mL}$ of dimethyl sulfoxide $\mathrm{d}_{6}$ (DMSO-d6).

Differential scanning calorimetry (TA Instruments DSC Q20, New Castle, DE, USA) was used to characterize the imine-compound-induced curing behavior of the epoxy resin. Dynamic mechanical analysis (DMA) was carried out on a TA Instruments DMA Q800 dynamic mechanical analyzer. The single-cantilever beam was used to deform the rectangular specimens with mean dimensions of $12.5 \times 1 \times 17.5 \mathrm{~mm}^{3}$. The frequency of the oscillation test was $1 \mathrm{~Hz}$, and the temperature dependence of the behavior was investigated in the temperature range from 20 to $200{ }^{\circ} \mathrm{C}$ at a heating rate of $3^{\circ} \mathrm{C} / \mathrm{min}$. In addition, stress-relaxation experiments were performed on the same mechanical analyzer. To maintain the straightness of the samples, initially, they were preloaded under a force of $0.001 \mathrm{~N}$. The samples were heated to the test temperature and were held there for $30 \mathrm{~min}$ to reach thermal equilibrium. Then, $1 \%$ strain was applied, and the stress needed to maintain constant $1 \%$ strain was recorded. The stress-relaxation moduli were obtained as a function of time.

The imine metathesis was studied by liquid chromatography-mass spectrometry (LC/MS) (AGILENT 6410B, Agilent Technologies, Wilmington, NC, USA). The equivalent molar ratio of imine compounds Van2HMDA and HBA2HMDA were dissolved separately in $\mathrm{MeOH}$, and the two solutions were mixed and stirred at room temperature. After one hour, the solvent was removed by vacuum evaporation at room temperature for the characterization.

The thermal healable of dynamic epoxy polymer was investigated by scratching test and was observed by scanning electron microscope (SEM) AIS2100C (Seron Technology, Ui-Wang, Korea). The surface of the film was coated with gold before observation. The surface of polymer was observed before scratch and after heating at $90^{\circ} \mathrm{C}$ for $5 \mathrm{~min}$.

Thermal stability of the epoxy polymer was analyzed by thermogravimetric analyzer (TGA, Instrument TA Q50, New Castle, DE, USA). Samples (10-20 mg) were loaded in a platinum pan and heated from 30 to $800{ }^{\circ} \mathrm{C}$ under a nitrogen at a heating rate of $20^{\circ} \mathrm{C} / \mathrm{min}$.

Tensile test was carried out by Universal Test Machines (LR Plus series, LLOYD Instrument, AMETEK, West Sussex, UK). The epoxy polymer was casted in a dog-bone-shaped mold. The specimens were loaded to failure at a speed of $0.5 \mathrm{~mm} / \mathrm{min}$.

The gel fraction test was conducted by immersing crosslinked epoxy samples in different solvents at room temperature under static conditions. After a week, the solvents were removed by filtration and the samples were dried at $110{ }^{\circ} \mathrm{C}$ for $24 \mathrm{~h}$. The gel fraction (GF) was calculated using the equation $G F=W_{2} / W_{1} \times 100$, where $W_{2}$ is the weight of the dry sample and $W_{1}$ is the weight of the original sample.

\section{Results and Discussion}

\subsection{Preparation of Dihydroxylimine Compound}

The imine was formed by a reversible condensation reaction between primary amine and carbonyl compounds. To enhance the yield of the reaction, benzene [34] were generally used as solvents to enable the removal of water formed by the condensation reaction by azeotropic distillation or by the addition of dehydrating agents. However, in this work, we found that the use of EtOH led to the imine compounds forming and precipitating out of the solution during the condensation reaction because of its low solubility in the reaction medium. Therefore, the condensation reaction is favorable for achieving a high product yield.

As shown in Figure S1a, the successful preparation of Van2HMDA was first confirmed by FT-IR analysis. The peak at $1673 \mathrm{~cm}^{-1}$ corresponding to a $\mathrm{C}=\mathrm{O}$ stretching vibration (black curve in Figure S1a) of the aldehyde carbonyl group of Van and the peak between 3400 and $3500 \mathrm{~cm}^{-1}$ corresponding to NH stretching (red curve in Figure S1a) of the primary amine (HMDA) disappeared after the formation of Van2HMDA. The peak at approximately $1640 \mathrm{~cm}^{-1}$ corresponding to $\mathrm{C}=\mathrm{N}$ stretching 
(Figure S1a, blue curve) of the imine group was clearly observed in the FT-IR spectrum of Van2HMDA. The broad peak at $3400 \mathrm{~cm}^{-1}$ corresponding to $\mathrm{OH}$ stretching vibration of hydroxyl group of Van (black curve in Figure S1a) also appeared on FT-IR curve of Van2HMDA (Figure S1a, blue curve), confirming its presence. Figure S1b shows the DSC curves of dihydroxylimine compound. The unique endothermal peak in the first heating curve (Figure S1b, black curve) with melting temperature around $129^{\circ} \mathrm{C}$ indicating homogeneous crystal structure and high purification of Van2HMDA. However, no exothermal peak upon cooling and no endothermal peak upon second heating (red curve and blue curve in Figure S1b) was observed, indicating the slow crystallization of Van2HMDA.

The dihydroxylimine compounds were further characterized by ${ }^{1} \mathrm{H}$ NMR and ${ }^{13} \mathrm{C}$ NMR. Figure S2 shows the corresponding spectra. The formation of an imine group was confirmed by the peak at $8.1 \mathrm{ppm}$ in the ${ }^{1} \mathrm{H}$ NMR spectrum, corresponding to the proton of an imine group (Figure S2a). The carbon of the imine group was also confirmed by the peak at $\sim 160 \mathrm{ppm}$ in the ${ }^{13} \mathrm{C}$ NMR spectrum (Figure S2b). The model compound, HBA2HMDA (4,4'-((hexane-1,6-diylbis(azanylylidene))bis(methanylylidene)) diphenol) was also characterized by ${ }^{1} \mathrm{H}$ NMR and ${ }^{13} \mathrm{C}$ NMR as shown in Figure S3.

\subsection{Imine Metathesis of the Model Compounds}

The imine $\mathrm{C}=\mathrm{N}$ bond can undergo three different exchange reactions: hydrolysis, transamination, and imine metathesis. The imine metathesis can be accelerated by an organic base catalyst such as L-proline [35]. However, the presence of a small amount of primary amine can also accelerate imine metathesis [22,24]. The mechanism of imine metathesis with the formation of cyclic four-membered transition states has also been studied $[22,24,25]$. In this work the imine metathesis was again confirmed experimentally with the model molecules as shown in Figure 1. Two imine compounds with and without a methoxy group on their aromatic ring and, as a result, the metathesis product from two imine compounds of different $\mathrm{m} / \mathrm{z}$ values were observed in the LC/MS spectrum after solutions of the two imine compounds were mixed. The new peak between the two starting peaks corresponds to the product of the imine metathesis reaction (blue line in Figure 1b).

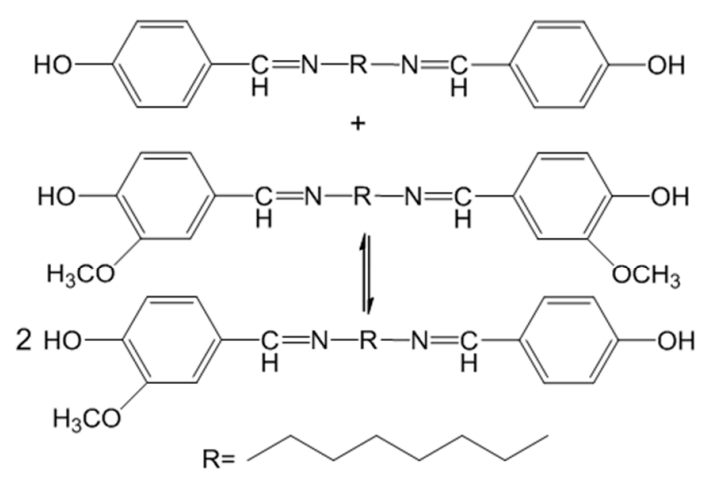

(a)

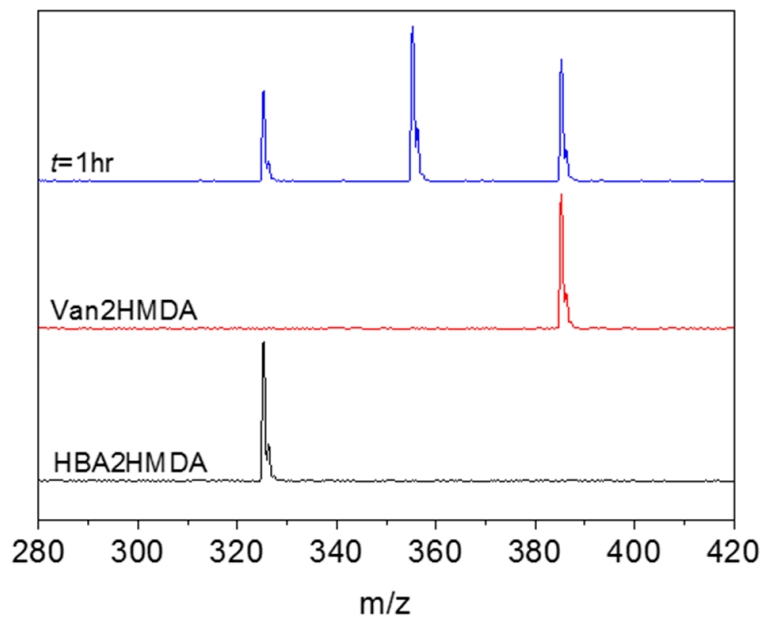

(b)

Figure 1. (a) Imine metathesis reaction between two imine compounds (Van2HMDA and HBA2HMDA) and (b) LC/MS spectra of imine compounds based on HBA2HMDA, Van2HMDA, and a mixture containing equivalent amounts of the two imine compounds in $\mathrm{MeOH}$ after $1 \mathrm{~h}(t=1 \mathrm{~h})$.

\subsection{Curing of Epoxy Resin by the Dihydroxylimine Compound}

Epoxy groups in the resins can react with amines, hydroxyls, anhydrides, acids or thiols [36-39]. The amines can directly react with an epoxy group in the absence of a catalyst or initiator, whereas other hardeners generally react with an epoxy group with a catalyst or initiator present. In this study, 
EMI-initiated reactions of the hydroxyl groups of the dynamic hardener (Figure 2a) and epoxy groups were carried out. The exothermic peak in the first scan DSC thermogram in Figure $2 b$ indicates an exothermic curing reaction between the hardener and the epoxy resin. The heat of cure was $133.6 \mathrm{~J} / \mathrm{g}$. In the second scan (Figure 2c), no exothermic peak was observed, indicating complete crosslinking of the epoxy resin after the first scan and a glass-transition temperature $\left(T_{\mathrm{g}}\right)$ of $78{ }^{\circ} \mathrm{C}$ for the crosslinked polymer, as determined from the enthalpy change.

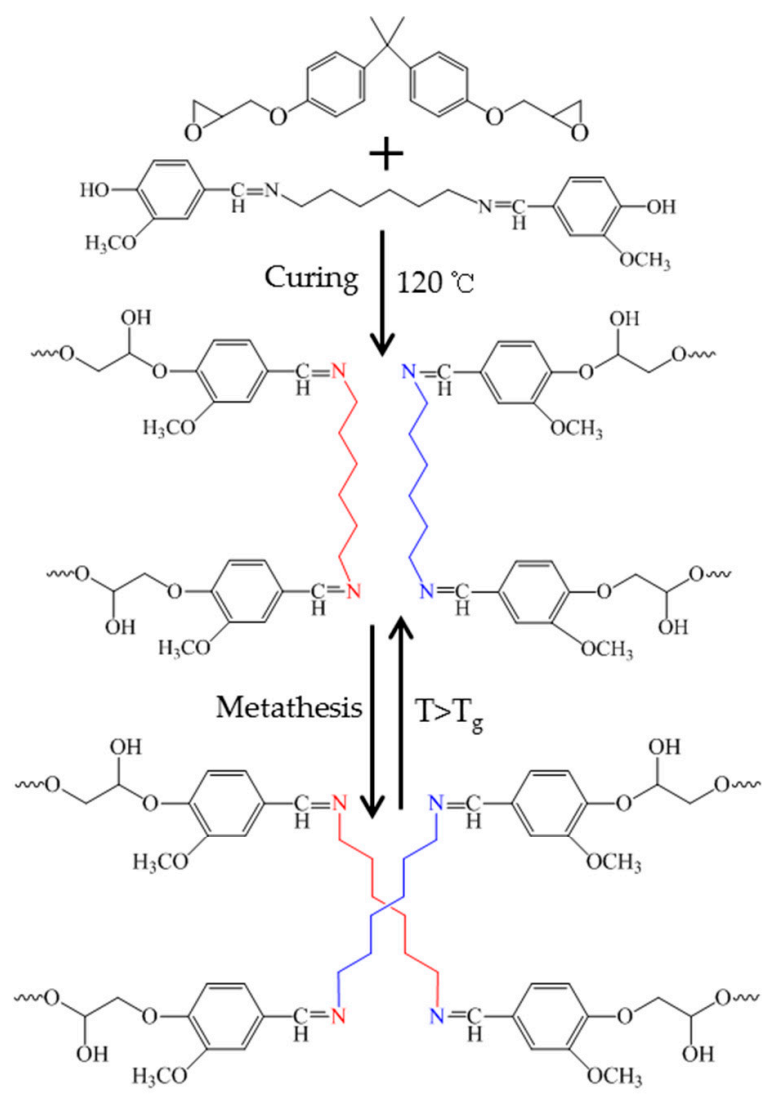

Dynamic epoxy polymer

(a)

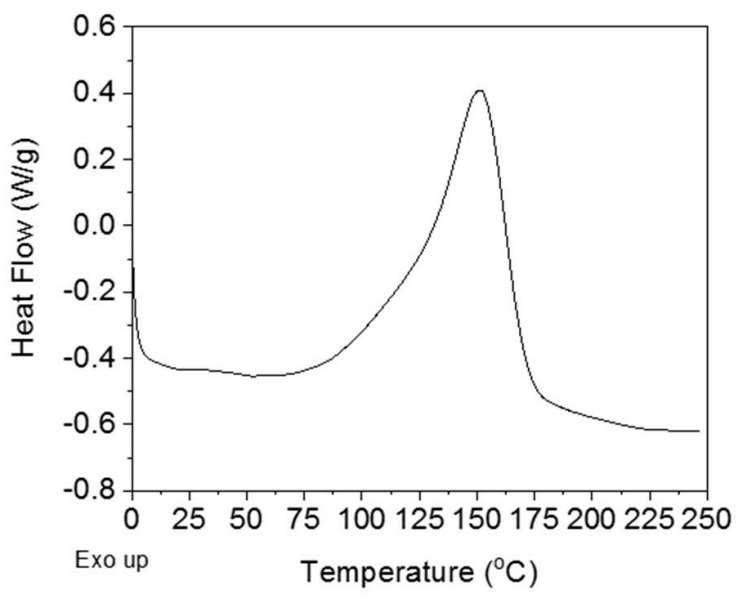

(b)

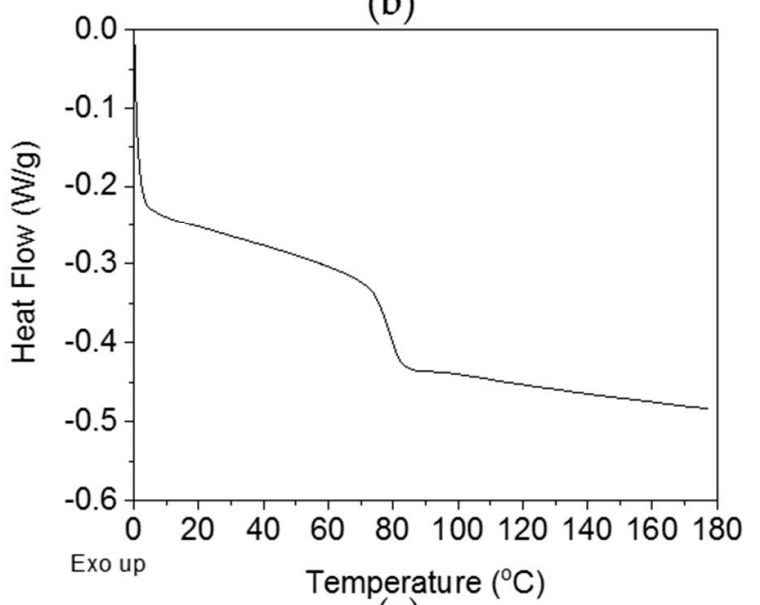

(c)

Figure 2. (a) Curing of bisphenol A-based epoxy resin by the dynamic hardener, Van2HMDA, and DSC thermograms of YD-128 cured by Van2HMDA: (b) 1st scan and (c) 2nd scan.

Figure 3a shows the storage modulus and tan delta of the epoxy resin cured by the dynamic hardener (Van2HMDA). A rubbery plateau is observed, and no melt flow zone appeared at temperatures up to $200^{\circ} \mathrm{C}$, indicating the crosslinked networks of epoxy polymer cured by dynamic imine hardener. The $T_{\mathrm{g}}$ identified from the tan delta of the epoxy cured by Van2HMDA was $87^{\circ} \mathrm{C}$, which is relatively low because of the inclusion of a flexible segment of hexamethylene in the dynamic hardener. Figure $3 \mathrm{~b}$ shows the thermal stability of dynamic epoxy polymer. The onset degradation temperature (temperature at $5 \mathrm{wt} \%$ loss) of dynamic epoxy polymer was $302.9^{\circ} \mathrm{C}$. In comparisons with conventional epoxy polymer, this temperature was lower due to low bonding energy of imine bond. The crosslinked epoxy resin exhibited tensile strength of $85 \mathrm{MPa}$ at elongation of $5.9 \%$ (Figure 3c). These mechanical properties were superior to those of dynamic polymers based on the transesterification [8] or disulfide metathesis [13].

The GF test is a typical test to compare the crosslink density of thermoset polymers. The un-crosslinked polymer is dissolved in commonly used solvents. Results of the GF indicate that 
the epoxy resin crosslinked with dynamic polymer did not dissolve in common solvents (Figure 3d). In polar solvents such as DMF and DMAc, the polymer swelled, followed by partial dissolution of the low-molecular-weight polymer, resulting in a lower GF compared with those of the samples immersed in nonpolar solvents (Figure S4). The imine bonds can undergo hydrolysis to release the aldehyde and amine. However, after 1 week of immersion in water, the weight and the shape of the dynamic epoxy film showed almost no change, indicating that hydrolysis reaction hardly occurred. The highly crosslinked network may prevent the hydrolysis reaction. However, the crosslinked epoxy polymer was easily dissolved in acid solution due to the hydrolysis of imine bonds with acid catalyst. Therefore, crosslinked epoxy polymer can be ecofriendly recycled.

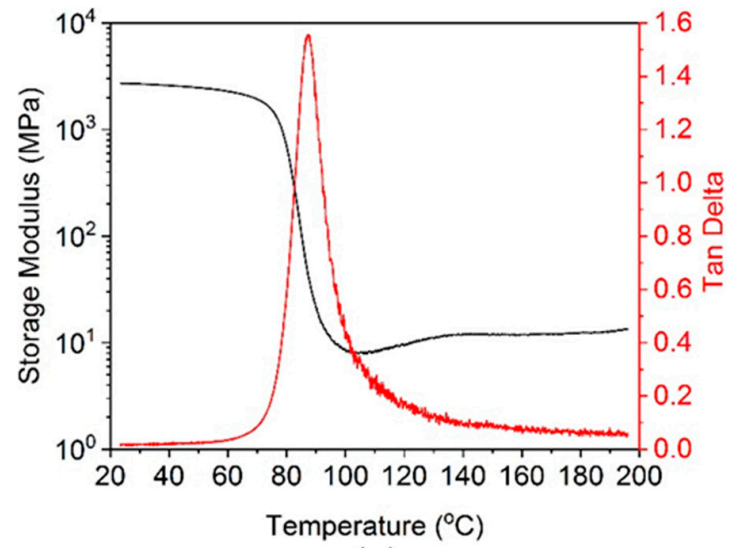

(a)

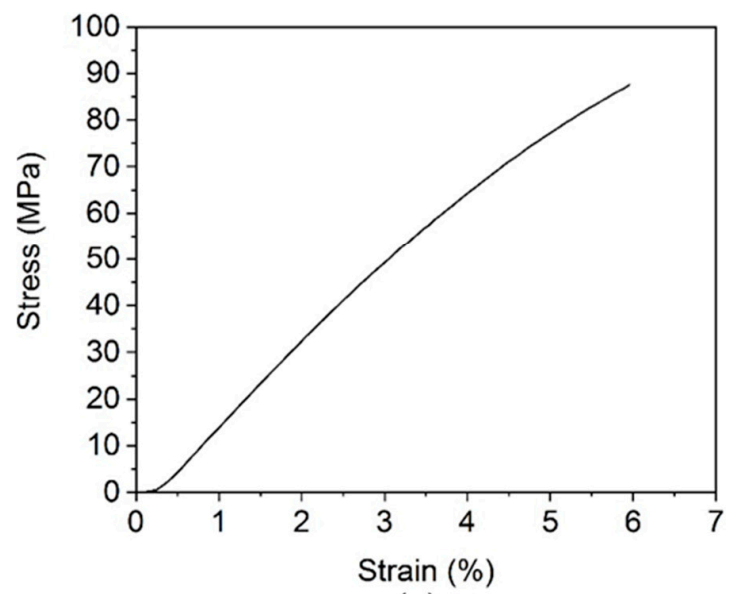

(c)

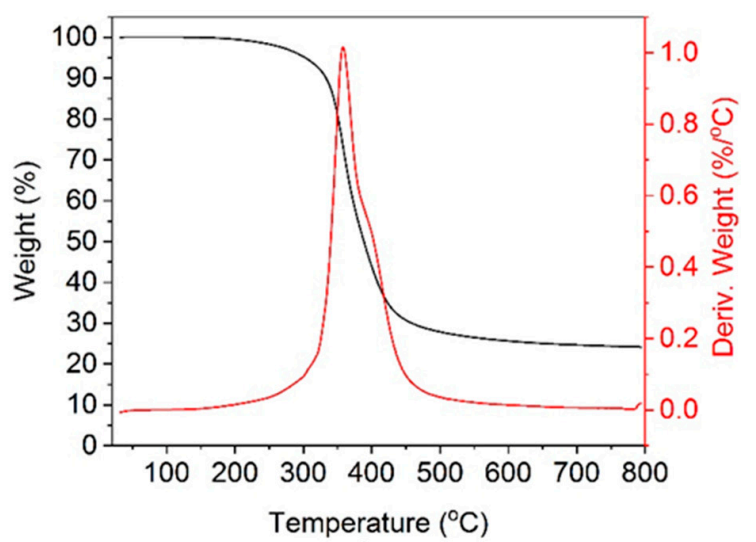

(b)

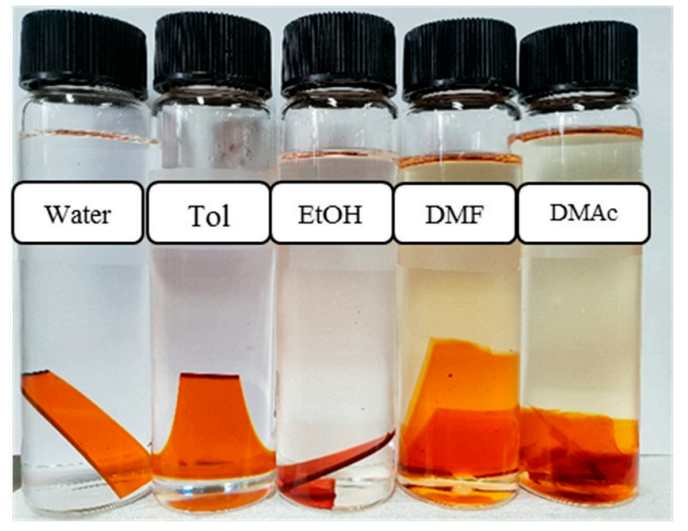

(d)

Figure 3. (a) DMA thermograms, (b) TGA thermograms, (c) Stress-strain behavior in tensile test, and (d) photographs of samples after a week of immersion in different solvents.

\subsection{Stress Relaxation of Crosslinked Epoxy Resin}

Polymers containing dynamic bonds can relax stress and flow [8], which is a typical behavior of polymers with dynamic covalent bonds. The stress-relaxation behavior of the epoxy resin cured by the dynamic hardener were analyzed by DMA and shown in Figure 4a. The results showed that the epoxy resin crosslinked with Van2HMDA was able to fully relax stress at a temperature greater than the $T_{\mathrm{g}}$. Furthermore, the stress-relaxation curves shifted to the left with increasing temperature because of the increase of the imine metathesis rate, enabling stress to relax more quickly. Relaxation times $\left(\tau^{*}\right)$ were defined based on Maxwell's model for viscoelastic materials as the time required to relax to $1 /$ e of the initial stress. The dynamic-hardener-based crosslinked epoxy resin in this study showed relaxation times that ranged from $60 \mathrm{~s}$ at $100^{\circ} \mathrm{C}$ to $10 \mathrm{~s}$ at $150^{\circ} \mathrm{C}$, which are much shorter than those of the crosslinked epoxy resins cured by fatty acids [8] or disulfide content hardeners $[12,13]$ 
reported in the literature indicating fast imine metathesis and rapid stress relaxation. The relationship between relaxation times and temperature according Arrhenius' law is given as follows:

$$
\tau(T)=\tau_{0} \exp \left(\frac{E_{a}}{R T}\right)
$$

where $\tau_{0}$ is the relaxation time at infinite $T, E_{\mathrm{a}}$ is the activation energy of the imine metathesis, and $R$ is the universal gas constant. Arrhenius plot of the relaxation time $\tau$ is shown in Figure $4 \mathrm{~b}$. From this fitting, an activation energy $\left(E_{\mathrm{a}}\right)$ of $44 \mathrm{~kJ} / \mathrm{mol}$ was obtained for the dynamic hardener crosslinked network of epoxy resin. This activation energy is much lower than the value of the crosslinked epoxy resins cured by fatty acids [8] or disulfide-based dynamic hardeners [12,13] reported previously.

The topology freezing transition temperature $\left(T_{\mathrm{v}}\right)$ is a key transition temperature for a dynamic polymer because, at the $T_{\mathrm{v}}$, the polymer transforms from vitrified glass to deformable solid as a consequence of the exchange reactions in the network. This transition is identified when the viscosity increases to greater than $10^{12} \mathrm{~Pa} \cdot \mathrm{s}$ [40]. From the Maxwell relation, $\eta=G \cdot \tau^{*}$, where $G$ is calculated from the elastic modulus, as measured by DMA, according to the relation $G=E^{\prime} / 2(1+v)(v=0.5$, the Poisson's ratio usually used for rubbers), where $G=E^{\prime} / 3$ and $E^{\prime}=11.56 \mathrm{MPa}$; thus, $\tau^{*}=2.6 \times 10^{5} \mathrm{~s}$. Substituting $\tau^{*}$ into the Arrhenius's equation, we can get the $T_{\mathrm{v}}$. For the epoxy resin cured by Van2HMDA, the hypothetical $T_{\mathrm{v}}$ value was $-38^{\circ} \mathrm{C}$, which is lower than its $T_{\mathrm{g}}\left(87^{\circ} \mathrm{C}\right.$, as determined by DMA), implying that an intrinsically fast imine metathesis occurred in a rigid polymer matrix. The value of $T_{\mathrm{v}}$ was calculated via extrapolation of stress-relaxation times; however, this transition is hypothetical because the network is not ultimately frozen by the reaction kinetics but by the lack of segmental motions associated with the $T_{\mathrm{g}}[41]$.

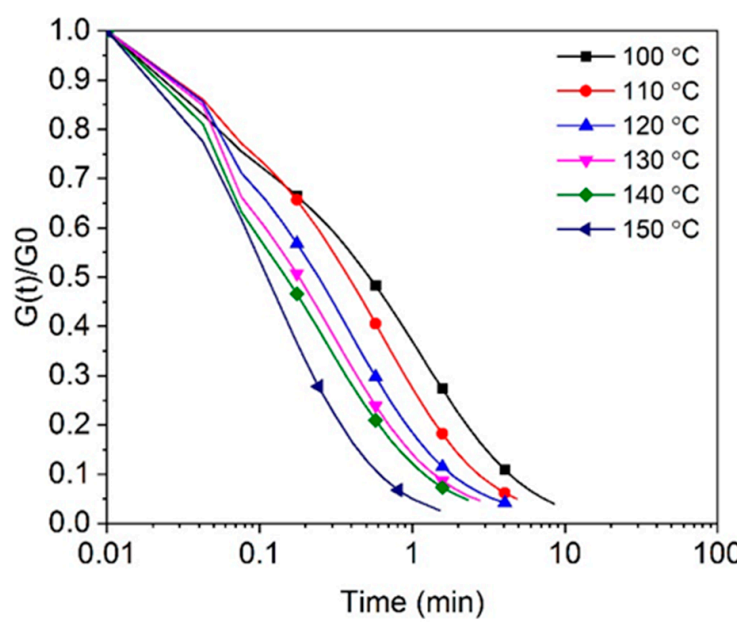

(a)

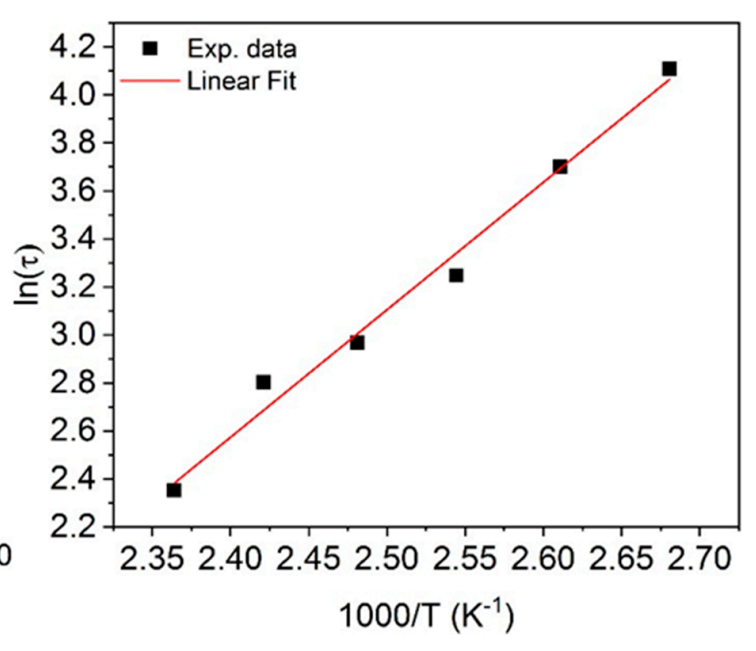

(b)

Figure 4. (a) Normalized stress-relaxation curves of the DGEBA-based epoxy resin cured by Van2HMDA at different temperatures; (b) Arrhenius plot of the relaxation times for the epoxy resins cured with Van2HMDA $\left(R^{2}=0.987\right)$.

\subsection{Thermal-Healing Properties and Reshaping Ability of the Crosslinked Epoxy Resin}

The thermal-healing tests were carried out by scratching of the surface of the films with a razor blade. The damaged film was heated on a hot plate at $90^{\circ} \mathrm{C}$ for $5 \mathrm{~min}$. Figure 5 a shows the surface of polymer with a scratch $50 \mu \mathrm{m}$ in width. After heating at $90^{\circ} \mathrm{C}$ for $5 \mathrm{~min}$, the scratch almost disappeared (Figure $5 b$ ). This temperature was higher than $T_{\mathrm{g}}$ therefore segmental motion was initiated that enables the polymer chains to diffuse into each other and the exchange reaction to occur. It is postulated that the healing process may start at the bottom of the scratch, where the distance between polymer molecules is sufficiently small for their chains to diffuse into each other. 
In addition, we tested the healing property of the crosslinked epoxy resin by overlapping two pieces of specimen after tensile test between two glass plates, pressing them with a paper clip and, then, heating at $110{ }^{\circ} \mathrm{C}$ for $15 \mathrm{~min}$ (insect picture in Figure $5 \mathrm{c}$ ). In this case, the crosslinked polymer molecules on the surface of the two pieces contacted each other because of stress. At high temperatures, the imine metathesis reaction occurred between these molecules, resulting in the healing of the two pieces. The tensile strength of healing sample was $10 \mathrm{MPa}$ (Figure $5 \mathrm{c}$ ), which was much lower than that of original sample because the failure occurred at healing area.

We confirmed the reshaping ability of the epoxy resin by heating a rectangular specimen to $90{ }^{\circ} \mathrm{C}$ on a hotplate and then twisting it. After the specimen was cooled to room temperature, it maintained its twisted shape (Figure 5d). The original shape of the film was recovered when the film was re-heated and applied the force. At temperatures greater than the $T_{\mathrm{g}}$, fast imine metathesis enables a change in the topology of the network and, upon cooling, the imine metathesis process becomes so slow that the topology of the network is essentially fixed [8].

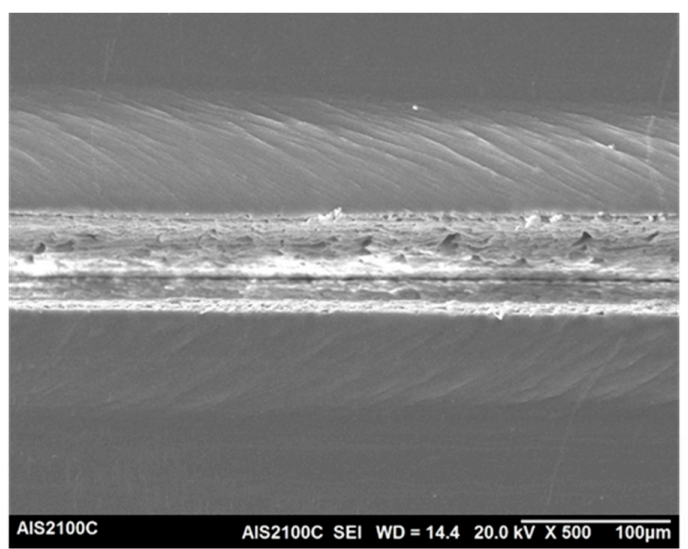

(a)

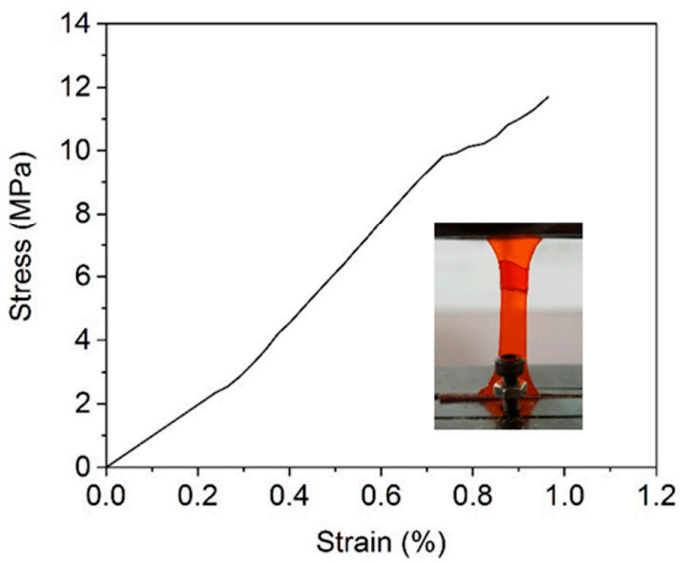

(c)

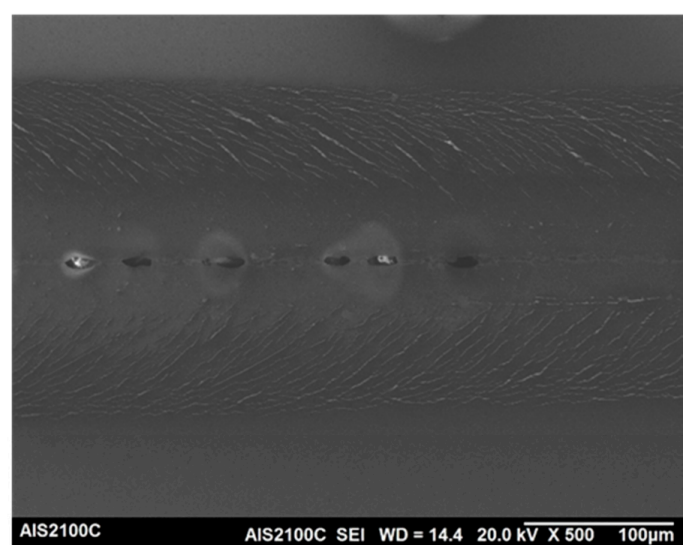

(b)

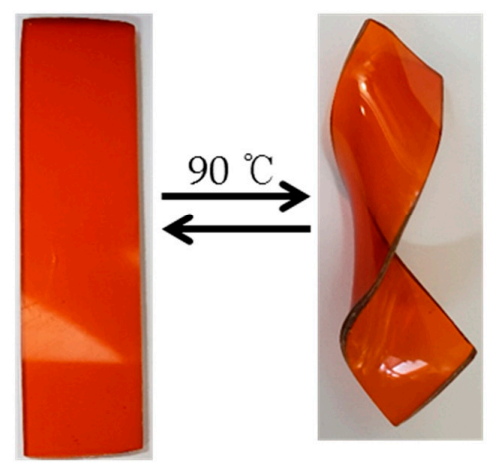

(d)

Figure 5. SEM images of (a) scratching surface and (b) the surface after heating at $90{ }^{\circ} \mathrm{C}$ for $5 \mathrm{~min}$; (c) stress-strain behavior in tensile test of rebounded specimen by overlapping and heating at $110{ }^{\circ} \mathrm{C}$ for $15 \mathrm{~min}$; (d) pictures showing the reshaping ability.

\subsection{Ecofriendly Recycling of Crosslinked Epoxy Polymer}

Due to the crosslinked network structures, the thermosetting polymer cannot be reprocessed or recycled. Introduction of dynamic covalent bonds for the reprocessing or recycling of network polymers requires harsh conditions $[12,13,23-25,29,42]$ such as high temperature, high pressure, additional monomer, and/or special catalyst. The imine bond can undergo three kinds of reversible reaction include hydrolysis (dissociative-type mechanism), transamination, and imine metathesis 
(associative-type mechanism). As shown above, imine metathesis could be used for thermal-healing and reshaping ability of crosslinked epoxy polymer. Then the hydrolysis of imine bond also could be used for ecofriendly recycling of crosslinked epoxy polymer.

Figure 6 shows recyclability or reprocessing of epoxy resin cured by Van2HMDA. The hydrolysis of imine bonds was confirmed by FT-IR (Figure 6b). After hydrolysis, the peak at $1643 \mathrm{~cm}^{-1}$ (Figure 6b, black curve) characterizing for imine bond of original polymer was disappeared in FT-IR spectrum of hydrolyzed polymer (Figure $6 \mathrm{~b}$, red curve). The reformation of aldehyde and primary amine were confirmed by presence of peaks at $1677 \mathrm{~cm}^{-1}$ and $3323 \mathrm{~cm}^{-1}$ (Figure $6 \mathrm{~b}$, red curve). However thermal stability of recycled polymer was inferior to that of original polymer (Figure $6 \mathrm{~d}$ ). The onset degradation temperature of the recycled polymer was $242{ }^{\circ} \mathrm{C}$, which is much lower than that of original polymer $\left(302{ }^{\circ} \mathrm{C}\right)$. The glass-transition temperature $\left(T_{\mathrm{g}}\right)$ of recycled polymer $\left(63^{\circ} \mathrm{C}\right)$ was lower than that of original polymer $\left(78^{\circ} \mathrm{C}\right)$ as given in Figure S5a. It is speculated that the condensation reaction between aldehyde and primary amine groups of the oligomers after chain scission via the hydrolysis of imine bonds could not be complete. Therefore, the crosslinking density of recycled polymer was lower than that of original polymer and the $T_{\mathrm{g}}$ was lowered. However, the recycled polymer still showed the reshaping and thermal-healing properties (Figure $S 5 b, c)$.

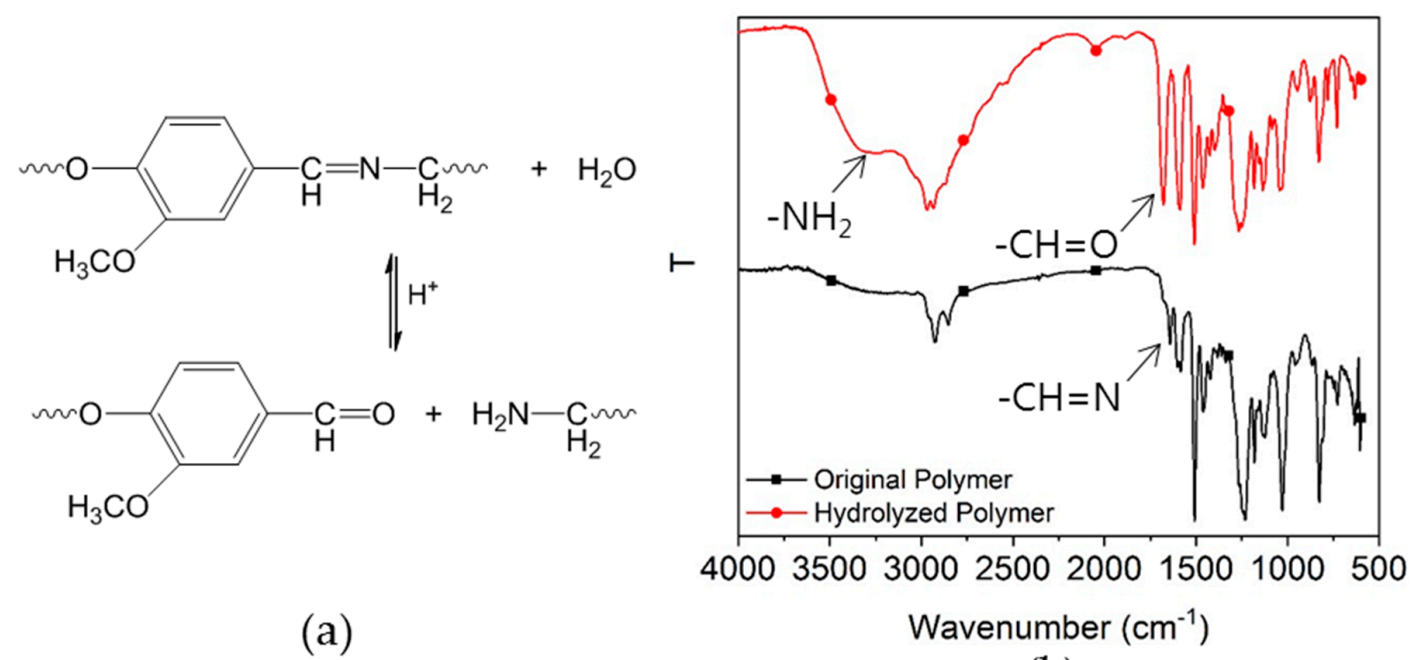

(b)

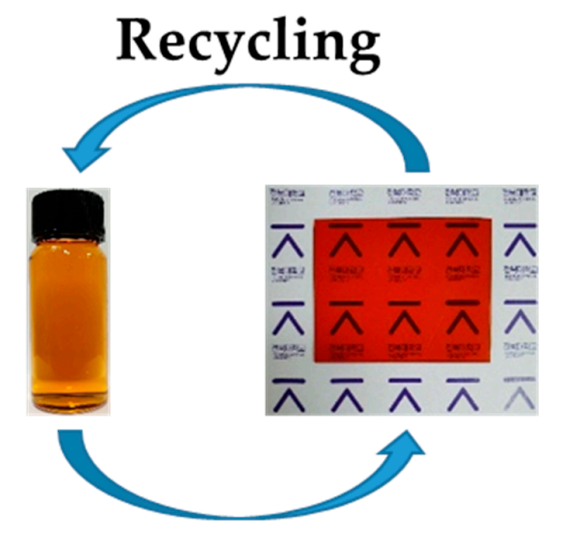

(c)

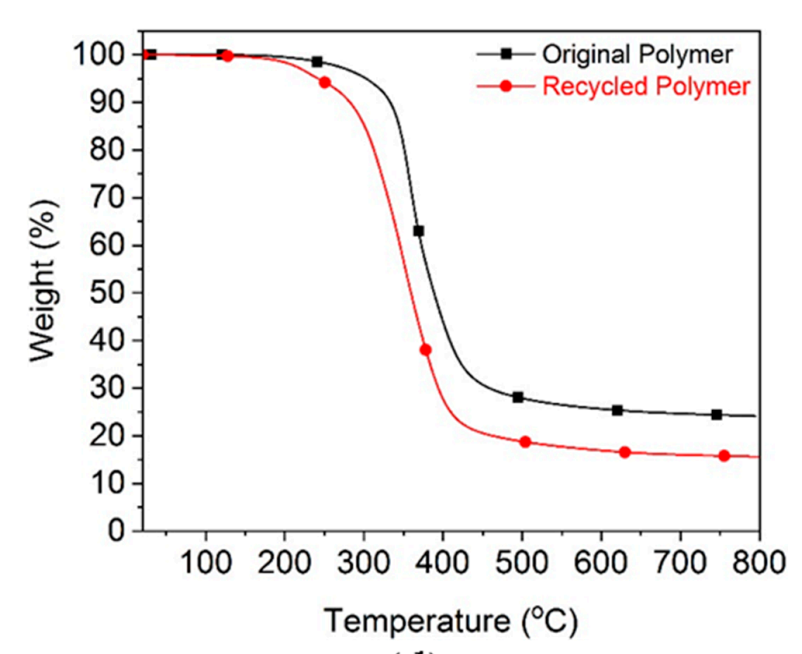

(d)

Figure 6. Recycling of epoxy resin crosslinked with Van2HMDA: (a) Hydrolysis of imine bonds; (b) FT-IR spectra of original polymer and hydrolyzed polymer; (c) Photographs show recyclability of the crosslinked epoxy resin; (d) TGA thermograms of original polymer and recycled polymer. 


\section{Conclusions}

In this study, we have shown a simple, environmentally friendly route to preparing a bio-derived dynamic hardener based on Van. The successful preparation of the dynamic hardener was confirmed by FT-IR and NMR analyses. The LC/MS spectra indicated imine metathesis of the model compounds. The dihydroxylimine compound can cure epoxy resin in a manner similar to the conventional hardener. The epoxy resin cured with a dynamic hardener exhibited fast stress relaxation because of rapid imine metathesis at temperatures greater than $T_{\mathrm{g}}$, enabling a dynamic crosslinked polymer with reshaping ability and thermal-healing ability. The dynamic epoxy polymer also shows ecofriendly recycle ability by using mild acid solution through hydrolysis of imine bonds. The recycled polymer shows lower thermal properties than that of original polymer due to lower crosslinking density. However, the recycled polymer still exhibits reshaping and thermal-healing ability.

Supplementary Materials: The following are available online at http:/ / www.mdpi.com/2073-4360/11/2/293/s1, Figure S1: (a) FT-IR spectra of Vanillin, HMDA, and the product (Van2HMDA) by Schiff-based formation and (b) DSC thermograms of Van2HMDA; Figure S2: (a) 1H-NMR and (b) 13C-NMR spectra of Van2HMDA based on Van and HMDA; Figure S3: (a) 1H-NMR and (b) 13C-NMR spectra of model compound HBA2HMDA based on HBA and HMDA; Figure S4: Gel fraction of the epoxy resin cured with Van2HMDA in different solvents; Figure S5: (a) DSC thermalgrams of original polymer and recycled polymer, (b) reshaping ability and (c) thermal-healing ability of recycled polymer.

Author Contributions: Conceptualization: D.S.L.; methodology: V.-D.M. and S.-R.S.; validation: D.S.L.; writing—original draft preparation: V.-D.M.; writing—review and editing: D.S.L.; project administration: D.S.L.; funding acquisition: D.S.L.

Acknowledgments: It is acknowledged that this work was supported by ATC project of KEIT funded by Ministry of Trade, Industry, and Energy (Project No: ATC-10048672) in Korea.

Conflicts of Interest: The authors declare no conflict of interest.

\section{References}

1. Brown, E.N.; White, S.R.; Sottos, N.R. Retardation and repair of fatigue cracks in a microcapsule toughened epoxy composite-Part II: In situ self-healing. Compos. Sci. Technol. 2005, 65, 2474-2480. [CrossRef]

2. White, S.R.; Sottos, N.R.; Geubelle, P.H.; Moore, J.S.; Kessler, M.R.; Sriram, S.R.; Brown, E.N.; Viswanathan, S. Autonomic healing of polymer composites. Nature 2001, 409, 794-797. [CrossRef] [PubMed]

3. Yin, T.; Rong, M.Z.; Zhang, M.Q.; Yang, G.C. Self-healing epoxy composites-Preparation and effect of the healant consisting of microencapsulated epoxy and latent curing agent. Compos Sci Technol. 2007, 67, $201-212$. [CrossRef]

4. Araya-Hermosilla, R.; Broekhuis, A.A.; Picchioni, F. Reversible polymer networks containing covalent and hydrogen bonding interactions. Eur. Polym. J. 2014, 50, 127-134. [CrossRef]

5. Dello Iacono, S.; Martone, A.; Pastore, A.; Filippone, G.; Acierno, D.; Zarrelli, M.; Giordano, M.; Amendola, E. Thermally activated multiple self-healing diels-alder epoxy system. Polym. Eng. Sci. 2017, 57, 674-679. [CrossRef]

6. Kuang, X.; Liu, G.M.; Dong, X.; Liu, X.G.; Xu, J.J.; Wang, D.J. Facile Fabrication of Fast Recyclable and Multiple Self-healing Epoxy Materials through Diels-Alder Adduct Cross-linker. J. Polym. Sci. Pol. Chem. 2015, 53, 2094-2103. [CrossRef]

7. Turkenburg, D.H.; Fischer, H.R. Diels-Alder based, thermo-reversible cross-linked epoxies for use in self-healing composites. Polymer 2015, 79, 187-194. [CrossRef]

8. Montarnal, D.; Capelot, M.; Tournilhac, F.; Leibler, L. Silica-Like Malleable Materials from Permanent Organic Networks. Science 2011, 334, 965-968. [CrossRef] [PubMed]

9. Shi, Q.; Yu, K.; Dunn, M.L.; Wang, T.J.; Qi, H.J. Solvent Assisted Pressure-Free Surface Welding and Reprocessing of Malleable Epoxy Polymers. Macromolecules 2016, 49, 5527-5537. [CrossRef]

10. Capelot, M.; Montarnal, D.; Tournilhac, F.; Leibler, L. Metal-Catalyzed Transesterification for Healing and Assembling of Thermosets. J. Am. Chem. Soc. 2012, 134, 7664-7667. [CrossRef]

11. Altuna, F.I.; Hoppe, C.E.; Williams, R.J.J. Shape memory epoxy vitrimers based on DGEBA crosslinked with dicarboxylic acids and their blends with citric acid. Rsc. Adv. 2016, 6, 88647-88655. [CrossRef] 
12. Ma, Z.Y.; Wang, Y.; Zhu, J.; Yu, J.R.; Hu, Z.M. Bio-Based Epoxy Vitrimers: Reprocessibility, Controllable Shape Memory, and Degradability. J. Polym. Sci. Pol. Chem. 2017, 55, 1790-1799. [CrossRef]

13. de Luzuriaga, A.R.; Martin, R.; Markaide, N.; Rekondo, A.; Cabanero, G.; Rodriguez, J.; Odriozola, I. Epoxy resin with exchangeable disulfide crosslinks to obtain reprocessable, repairable and recyclable fiber-reinforced thermoset composites. Mater. Horiz. 2016, 3, 241-247. [CrossRef]

14. Lei, Z.Q.; Xiang, H.P.; Yuan, Y.J.; Rong, M.Z.; Zhang, M.Q. Room-Temperature Self-Healable and Remoldable Cross-linked Polymer Based on the Dynamic Exchange of Disulfide Bonds. Chem. Mater. 2014, 26, 2038-2046. [CrossRef]

15. Gao, W.T.; Bie, M.Y.; Liu, F.; Chang, P.S.; Quan, Y.W. Self-Healable and Reprocessable Polysulfide Sealants Prepared from Liquid Polysulfide Oligomer and Epoxy Resin. Acs. Appl. Mater. Inter. 2017, 9, 15798-15808. [CrossRef] [PubMed]

16. Canadell, J.; Goossens, H.; Klumperman, B. Self-Healing Materials Based on Disulfide Links. Macromolecules 2011, 44, 2536-2541. [CrossRef]

17. Lu, Y.X.; Guan, Z.B. Olefin Metathesis for Effective Polymer Healing via Dynamic Exchange of Strong Carbon-Carbon Double Bonds. J. Am. Chem. Soc. 2012, 134, 14226-14231. [CrossRef]

18. Lai, J.C.; Mei, J.F.; Jia, X.Y.; Li, C.H.; You, X.Z.; Bao, Z.A. A Stiff and Healable Polymer Based on Dynamic-Covalent Boroxine Bonds. Adv. Mater. 2016, 28, 8277-8282. [CrossRef]

19. Cromwell, O.R.; Chung, J.; Guan, Z.B. Malleable and Self-Healing Covalent Polymer Networks through Tunable Dynamic Boronic Ester Bonds. J. Am. Chem. Soc. 2015, 137, 6492-6495. [CrossRef]

20. Kuhl, N.; Bode, S.; Bose, R.K.; Vitz, J.; Seifert, A.; Hoeppener, S.; Garcia, S.J.; Spange, S.; van der Zwaag, S.; Hager, M.D.; et al. Acylhydrazones as Reversible Covalent Crosslinkers for Self-Healing Polymers. Adv. Funct. Mater. 2015, 25, 3295-3301. [CrossRef]

21. Layer, R.W. Chemistry of Imines. Chem. Rev. 1963, 63, 489. [CrossRef]

22. Ciaccia, M.; Cacciapaglia, R.; Mencarelli, P.; Mandolini, L.; Di Stefano, S. Fast transimination in organic solvents in the absence of proton and metal catalysts. A key to imine metathesis catalyzed by primary amines under mild conditions. Chem. Sci. 2013, 4, 2253-2261. [CrossRef]

23. Taynton, P.; Zhu, C.P.; Loob, S.; Shoemaker, R.; Pritchard, J.; Jin, Y.H.; Zhang, W. Re-healable polyimine thermosets: Polymer composition and moisture sensitivity. Polym. Chem.-UK 2016, 7, 7052-7056. [CrossRef]

24. Chao, A.; Negulescu, J.; Zhang, D.H. Dynamic Covalent Polymer Networks Based on Degenerative Imine Bond Exchange: Tuning the Malleability and Self-Healing Properties by Solvent. Macromolecules 2016, 49, 6277-6284. [CrossRef]

25. Lei, Z.Q.; Xie, P.; Rong, M.Z.; Zhang, M.Q. Catalyst-free dynamic exchange of aromatic Schiff base bonds and its application to self-healing and remolding of crosslinked polymers. J. Mater. Chem. A 2015, 3, 19662-19668. [CrossRef]

26. Stuparu, M.C.; Khan, A.; Hawker, C.J. Phase separation of supramolecular and dynamic block copolymers. Polym. Chem.-UK 2012, 3, 3033-3044. [CrossRef]

27. Rao, J.Y.; Khan, A. Using reversibility of the dynamic covalent bond to create porosity in highly ordered polymer thin films under mild conditions and nano-pore functionalization in the gas phase. Polym. Chem.-UK 2013, 4, 2691-2695. [CrossRef]

28. Rao, J.Y.; De, S.; Khan, A. Synthesis and self-assembly of dynamic covalent block copolymers: Towards a general route to pore-functionalized membranes. Chem. Commun. 2012, 48, 3427-3429. [CrossRef]

29. Abu-Omar, S.Z.M.M. Recyclable and Malleable Epoxy Thermoset Bearing Aromatic Imine Bonds. Macromolecules 2018, 51, 9816-9824. [CrossRef]

30. Koike, T. Progress in Development of Epoxy Resin Systems Based on Wood Biomass in Japan. Polym. Eng. Sci. 2012, 52, 701-717. [CrossRef]

31. Aouf, C.; Lecomte, J.; Villeneuve, P.; Dubreucq, E.; Fulcrand, H. Chemo-enzymatic functionalization of gallic and vanillic acids: Synthesis of bio-based epoxy resins prepolymers. Green. Chem. 2012, 14, 2328-2336. [CrossRef]

32. Fache, M.; Darroman, E.; Besse, V.; Auvergne, R.; Caillol, S.; Boutevin, B. Vanillin, a promising biobased building-block for monomer synthesis. Green. Chem. 2014, 16, 1987-1998. [CrossRef]

33. da Silva, E.A.B.; Zabkova, M.; Araujo, J.D.; Cateto, C.A.; Barreiro, M.F.; Belgacem, M.N.; Rodriques, A.E. An integrated process to produce vanillin and lignin-based polyurethanes from Kraft lignin. Chem. Eng. Res. Des. 2009, 87, 1276-1292. [CrossRef] 
34. Krassig, H.; Greber, G. Uber Die Umsetzungen Von Terephthalaldehyd Mit Aliphatischen Diaminen. 431. Mitteilung Uber Makromolekulare Verbindungen. Makromolekul Chem. 1956, 17, 131-153. [CrossRef]

35. Wilhelms, N.; Kulchat, S.; Lehn, J.M. Organocatalysis of $C=N / C=N$ and $C=C / C=N$ Exchange in Dynamic Covalent Chemistry. Helv. Chim. Acta 2012, 95, 2635-2651. [CrossRef]

36. Muzammil, E.M.; Khan, A.; Stuparu, M.C. Post-polymerization modification reactions of poly(glycidyl methacrylate)s. Rsc. Adv. 2017, 7, 55874-55884. [CrossRef]

37. Stuparu, M.C.; Khan, A. Thiol-epoxy "click" chemistry: Application in preparation and postpolymerization modification of polymers. J. Polym. Sci. Pol. Chem. 2016, 54, 3057-3070. [CrossRef]

38. Hwang, J.; Lee, D.G.; Yeo, H.; Rao, J.; Zhu, Z.; Shin, J.; Jeong, K.; Kim, S.; Jung, H.W.; Khan, A. Proton Transfer Hydrogels: Versatility and Applications. J. Am. Chem. Soc. 2018, 140, 6700-6709. [CrossRef] [PubMed]

39. Cengiz, N.; Rao, J.Y.; Sanyal, A.; Khan, A. Designing functionalizable hydrogels through thiol-epoxy coupling chemistry. Chem. Commun. 2013, 49, 11191-11193. [CrossRef]

40. Calvert, P. Introduction to Physical Polymer Science-Sperling, L.H. Nature 1987, 326, 216. [CrossRef]

41. Denissen, W.; Winne, J.M.; Du Prez, F.E. Vitrimers: Permanent organic networks with glass-like fluidity. Chem. Sci. 2016, 7, 30-38. [CrossRef] [PubMed]

42. Li, L.Q.; Chen, X.; Jin, K.L.; Torkelson, J.M. Vitrimers Designed Both To Strongly Suppress Creep and To Recover Original Cross-Link Density after Reprocessing: Quantitative Theory and Experiments. Macromolecules 2018, 51, 5537-5546. [CrossRef]

(C) 2019 by the authors. Licensee MDPI, Basel, Switzerland. This article is an open access article distributed under the terms and conditions of the Creative Commons Attribution (CC BY) license (http:/ / creativecommons.org/licenses/by/4.0/). 